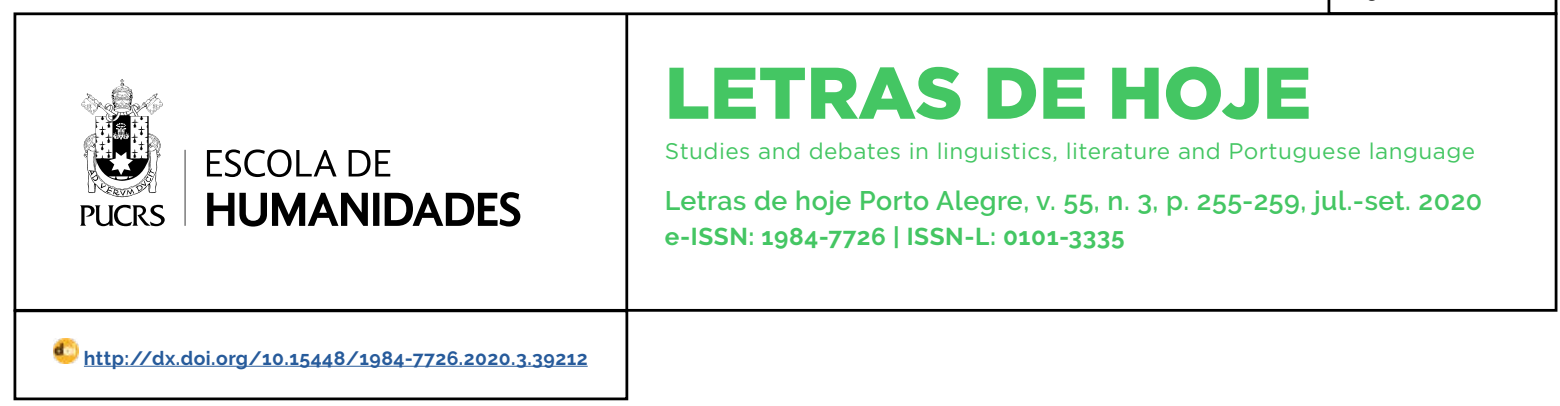

EDITORIAL - TEMÁTICA LIVRE

\title{
A linguagem na vida e a linguagem na abstração
}

\author{
Cláudio Primo Delanoy ${ }^{1}$ \\ orcid.org/0000-0002-8015-5349 \\ claudio.delanoy@pucrs.br
}

Recebido em: 23/09/2020

Aprovado em: 23/09/2020

Publicado em: 17/12/2020

\section{(c) (i)}

Artigo está licenciado sob forma de uma licença Creative Commons Atribuição 4.0 Internacional.
Abrimos este número da revista Letras de Hoje com pesquisas no campo da Linguística. Instaurou-se um desafio para encontrarmos uma unidade, já que os trabalhos se apresentam com temas variados. Na verdade, de certo modo, este volume representa a ciência linguistica, sendo tão multifacetada, que envolve desde a pesquisa de unidades mínimas da língua até a análise global de discursos (sem intencionarmos polarizar os estudos linguisticos, mas unicamente tentando demonstrar a amplitude de objetos de pesquisas na área). Uma solução óbvia foi buscar o elemento integrador na base, ou seja, na própria linguagem. Mas ainda assim, sentimos a necessidade de especificação. Diante dos dez trabalhos tão diversos aqui presentes, pensamos que seu ponto de encontro seria o estudo da linguagem em relação à práxis, quer dizer, as pesquisas voltadas para uma perspectiva de linguagem em sua realidade, diferentemente do estudo de uma abordagem teórica com fins em si mesma.

A crítica ao teoricismo puro nas investigações da linguagem encontrou voz no pensador russo Mikhail Bakhtin e nos seus parceiros do Círculo. A seu ver, os estudos teóricos apoiados em abstrações linguísticas não são de grande poder descritivo e explicativo da linguagem real, pois desconsideram a existência do ato singular que é a produção linguística, ato pelo qual o ser ocupa um lugar na vida e responde por si. Afirma-nos Bakhtin:

Nenhuma orientação prática da minha vida no mundo teórico é possivel: nele não é possivel viver, agir responsavelmente, nele não sou necessário, nele, por principio, não tenho lugar. O mundo teórico se obtém por uma abstração que não leva em conta o fato da minha existência singular e do sentido moral deste fato, que se comporta "como se eu não existisse" [...] (BAKHTIN, 2010, p. 52).

O mundo teórico é o mundo da repetibilidade, da previsibilidade. É um sistema fechado em si mesmo, dado como pronto, acabado. Dele é excluido o caráter de evento único do ato de linguagem, sua historicidade. Entendemos, então, a crítica de Bakhtin: não há vida no teoricismo abstrato, e, se a linguagem é estudada à parte da vida, perde sua natureza. O ser que the dá existência é retirado. Sua essência é substituida pela indiferença teórica.

No texto Para uma filosofia do ato responsável, Bakhtin (2010) desenvolve o raciocínio: cada ato concreto de linguagem pode servisto como um Jano 
bifronte, o deus romano de duas faces opostas. Uma face estaria voltada ao conteúdo objetivo da cultura, dentro do qual está a ciência, e a outra para a singularidade do ato único e irrepetivel. $\mathrm{O}$ mundo da cultura representa todas as experiências e conquistas humanas em termos de sociedade, tais como a ciência, a religião, a política, a filosofia, a educação, a arte. O mundo da vida é onde se desenvolve concretamente a existência de cada um, em sua individualidade, em sua característica única e insubstituível. Para o pensador russo, ambos são mundos incomunicáveis, mas que podem ser integrados. Nessa oposição, o plano de encontro está somente no "evento singular do existir no seu efetuar-se" (BAKHTIN, 2010, p. 43). Se considerarmos a linguagem como condição existencial para esses mundos, já que sem linguagem a sociedade seria impossivel, o estudo da linguagem também pode ocupar cada um desses mundos e integrá-los em sua realidade.

No entanto, Bakhtin e seus parceiros de reflexão não negam as conquistas advindas da abstração. Defendem o estudo da linguagem justamente a partir da integração dos dois mundos. Partem do principio de que a linguagem não deve ser dissociada de sua característica viva, de sua face como evento único.

A concepção de linguagem para Bakhtin e o Círculo (dentre seus parceiros de reflexões citamos Volóchinov e Medviédev) requer considerar seu ato concreto de realização, ou seja, envolve uma situação real de enunciação: todo ato de linguagem é concebido por um falante e direcionado a um interlocutor, seja real ou imaginário, individual ou coletivo, seres organizados numa sociedade e imersos num mundo de cultura. Tal ato linguageiro não se dá por meio de combinação de signos abstratos, mas por enunciados concretos que dialogam entre si, como se respondessem uns aos outros:

A realidade efetiva da linguagem não é o sistema abstrato de formas linguisticas nem o enunciado monológico isolado, tampouco o ato psicofisiológico de sua realização, mas o acontecimento social da interação discursiva que ocorre por meio de um ou de vários enunciados (VOLÓCHINOV, 2017, p. 218, grifo do autor).
É o princípio do dialogismo constituindo a natureza da linguagem, conceito unificador de toda a teoria de Bakhtin e o Círculo. O dialogismo ultrapassa o diálogo face a face, sua manifestação mais evidente, para expressar a natureza da linguagem. Todo enunciado é construido a partir de outros precedentes, e a eles mostra-se como uma resposta. Produzimos discurso por meio de enunciados-respostas, e por eles marcamos nossa individualidade, e com ela, nossa responsabilidade.

A responsabilidade advinda do ato de enunciação vai além de o locutor marcar-se por eu, por usar a adjetivação e advérbios avaliativos, dentre outros procedimentos indicativos linguísticos de subjetividade. O ato é responsável porque o sujeito não tem como escapar da linguagem. A enunciação é sempre única:

Cada um de meus pensamentos, com o seu conteúdo, é um ato singular responsável meu: é um dos atos de que se compõe a minha vida singular inteira como agir ininterrupto, porque a vida inteira na sua totalidade pode ser considerada como uma espécie de ato complexo: eu ajo com toda a minha vida, e cada ato singular e cada experiência que vivo são um momento do meu viver-agir. Tal pensamento, enquanto ato, forma um todo integral: tanto o seu conteúdo-sentido quanto o fato de sua presença em minha consciência real de um ser humano singular, precisamente determinado e em condições determinadas - ou seja, toda a historicidade concreta de sua realização - estes dois momentos, portanto, seja o do sentido, seja o histórico-individual (factual), são dois momentos unitários e inseparáveis na valoração deste pensamento como meu ato responsável (BAKHTIN, 2010, p. 44).

O sentido de um enunciado, portanto, não pode ser reduzido ao seu conteúdo linguístico. Há todo um conjunto de fatores históricos, sociais, ideológicos, culturais, que contribuem para a construção de um sentido único a cada ato enunciativo do ser falante. Uma linguística voltada à realidade da linguagem, que pretende dar um retorno à sociedade, recorre à teoricidade, necessária para a constituição do objeto, mas não desconsidera o uso, a aplicabilidade da pesquisa. Aqui retornamos a esta edição da revista.

Estão reunidos artigos com diversos enfoques teóricos e metodológicos, com distintas propostas de pesquisa. São trabalhos sobre arte e 
linguagem, tradução, estudos gramaticais, ensino e aprendizagem de língua, vivências escolares, gêneros discursivos, dentre outros temas. Porém, conforme indicamos no início deste texto, todos, de alguma forma, respondem à sociedade, no sentido de dar a ela um retorno. As autoras e os autores assumiram a responsabilidade de responder com sua pesquisa a um problema, a uma falta percebida muitas vezes no próprio campo de atuação da linguagem. É nesse sentido que concordamos com Bakhtin quanto à necessidade do estudo da linguagem viva.

Este número da Letras de Hoje abre com o texto de Laura Utrera, intitulado "Las transfiguraciones del Arte en la agenda de los Objetivos de Desarrollo Sostenible 2030. Algunos apuntes sobre el aporte de las Humanidades y las Artes a la agenda". No âmbito da Agenda 2030 para o Desenvolvimento Sustentável do Mundo, discutida pelas Nações Unidas em 2015, a pesquisadora reflete sobre as contribuições das humanidades e das artes para o desenvolvimento sustentável do planeta, bem como para o fortalecimento da democracia na América Latina. A autora dialoga com Graciela Speranza, Martha Nussbaum, Barthes, Bernabé e Horacio Quiroga para analisar as ações das humanidades e das artes para a construção de uma perspectiva mais saudável de nossa sociedade.

Mariano Nicolás Zucchi apresenta seu trabalho "Representaciones de las lenguas en La terquedad de Rafael Spregelburd". O autor analisa e avalia a coexistência do inglês, do valenciano de outras variedades do espanhol na referida obra de Rafael Spregelburd. Na visão do autor, as linguas assumem acentos valorativos que vão compor o sentido do texto. Tais representações são analisadas pelo viés do enfoque dialógico e da polifonia a partir das pesquisas da linguista María Marta García Negroni.

A seguir, temos um artigo de Jiayuan Zhou e Yuqi Sun. Em "Omissão na interpretação consecutiva de português para chinês por aprendentes chineses: uma análise das unidades de interpretação dos textos jornalísticos", estudam o tema do apagamento de partes do discurso em processo de interpretação consecutiva e as con- sequências para o sentido. O objetivo é levantar e analisar as causas das omissões realizadas por estudantes chineses do curso de pós-graduação da Universidade de Macau, relacionando estados psicológicos e cognitivos dos alunos. As análises são feitas a partir do aporte teórico das Unidades de Tradução sugeridas por Gile.

Na continuação, o artigo "Conhecimento linguístico do letrado acerca das expressões de futuridade = forma perifrástica (gramática nuclear/ L1) + forma sintética (gramática periférica/L2)", de Paulo Ângelo Araújo-Adriano, aborda o tema aquisição e frequência de uso de expressões de futuridade por crianças em fase de aquisição da linguagem, por estudantes de nível básico e de nivel superior, contrastando com dados do português brasileiro entre os séculos XVI e XXI. Ao tomar a aquisição natural do português como $L 1$ e o ensinado na escola como L2, o autor pesquisa as ocorrências de expressões verbais indicativas de futuro nas modalidades oral e escrita dos estudantes a partir do viés da Sintaxe Gerativa de Chomsky, dentre outras referências.

O artigo de Pâmela Lopes Vicari e Kári Lúcia Forneck, "Em outras palavras, o que esse texto quer dizer? A paráfrase no ensino da compreensão leitora", desenvolve o tema do ensino de paráfrases a alunos de $9^{\circ}$ ano do Ensino Fundamental como uma estratégia de desenvolvimento da compreensão leitora. A pesquisa, conforme as autoras, não atingiu plenamente o objetivo de estabelecer a paráfrase como potencializadora da compreensão leitora. No entanto, permitiu a emergência de reflexões relacionadas às dificuldades de compressão de textos por parte dos alunos, bem como a necessidade de ampliação de mais estudos sobre o ensino de leitura e trabalhos de intervenções didáticas.

Mantendo-nos no âmbito escolar, o artigo "Fenômenos representativos de adolescentes em contexto socioeducativo sobre escolarização, abandono escolar e aulas de língua materna", de Sabrina Cecilia Moraes Bastos e Cátia de Azevedo Fronza, levanta a problemática da relação entre adolescentes em situação socioeducativa e a escola. O estudo das autoras, com base na Teoria 
das Representações Sociais, Identidade, Diferença e estudos sobre a educação de adolescentes em conflito com a lei, no campo da linguística aplicada, conclui que a escola apresenta potencial para a reabilitação social desses jovens, contribuindo para que construam uma visão de mundo não mais excludente.

O trabalho de Viviane Cristina Mattos Battistello, Ana Teresinha Elicker, Lovani Volmer e Rosemari Lorenz Martins tem o título "A contação de histórias para crianças autistas". Com a temática do letramento voltado a crianças autistas, as autoras relatam uma prática de mediação de leitura, por meio de fábulas, para crianças pré-escolares autistas com nível leve. Os resultados foram positivos ao confirmarem os processos relevantes de socialização das crianças advindos da mediação de leitura e ao contribuírem para o desenvolvimento do letramento emergente.

O texto de Márcia Helena de Melo Pereira e Anne Carolline Dias Rocha Prado, denominado "Gêneros discursivos e Crítica Genética: pontos de contato", mostra a aplicação das teorias de Bakhtin e da Crítica Genética na produção de uma resenha em dupla para investigar o processo construtivo do discurso. A aproximação entre as abordagens teóricas permitiu a revelação de processos construtivos do referido gênero, inacessiveis se o olhar focalizar unicamente o produto.

O trabalho de Ana Maria Tramunt Ibaños e Yuri Fernando da Silva Penz, "Significado complexo e Racionalidade ampla: alguns insights em Filosofia da Linguagem", investiga a cognição humana por meio dos conceitos de significado complexo e racionalidade ampla, no âmbito de uma linguística interdisciplinar. Para tanto, os autores recorrem às reflexões de cientistas renomados como Bloomfield, Chomsky, Saussure, George Lakoff, Sperber e Wilson, dentre outros, todos ocupados com a pesquisa semântica da linguagem.

Fechando este número da revista, trazemos o artigo "O nacionalismo nas matrizes ideológicas do discurso político: a argumentação no impeachment de Dilma Rousseff", de Frederico Rios C. dos Santos. O autor dedica-se a analisar as falas na Câmara dos Deputados que resultaram no afastamento da ex- -presidente. Ao veicular um tom nacionalista, grande parte dos discursos dos deputados deixou transparecer a retórica política conservadora de direita. Para chegar a esse resultado, o pesquisador buscou embasamento em Bobbio e em Charaudeau.

Ao finalizarmos esta apresentação, em todos os trabalhos acima, vemos a linguagem tomada como o elemento essencial nas relações humanas, a linguagem que fundamenta a arte, que possibilita a comunicação, que revela potencialidades e fragilidades do humano em interação no mundo. Afirma-nos Volóchinov:

Por fim, é óbvio que sem a ajuda da palavra
não teriam surgido a ciência, a literatura etc.,
em suma, nenhuma cultura poderia ter existido
se a humanidade tivesse sido privada da pos-
sibilidade da comunicação social, cuja forma
materializada é a nossa língua (VOLÓCHINOV,
2019, p. 251, grifo do autor).

Retornando à nossa proposta de garantir uma unidade a este número da Letras de Hoje, se não reunimos os textos em uma linha norteadora temática concentrada em área específica, buscamos a essência do trabalho científico teórico voltado à resposta de algum problema. A pesquisa na linguística, então, responde a necessidades da sociedade.

\section{Referências}

BAKHTIN, Mikhail. Para uma filosofia do ato responsável. Trad. Valdemir Miotello e Carlos Alberto Faraco. São Carlos: Pedro \& João, 2010.

VOLÓCHINOV, Valentin. Marxismo e filosofia da linguagem: problemas fundamentais do método sociológico na ciência da linguagem. Tradução Sheila Grillo e Ekaterina Vólkova Américo. São Paulo: 34, 2017.

VOLÓCHINOV, Valentin. A palavra na vida e a palavra na poesia: ensaios, artigos, resenhas e poemas. Org. e trad. Sheila Grillo e Ekaterina Vólkova Américo. São Paulo: 34, 2019.

\section{Cláudio Primo Delanoy}

Doutor em Letras/ Linguística pela Pontificia Universidade Católica do Rio Grande do Sul (PUCRS), em Porto Alegre, RS, Brasil; professor da Escola de Humanidades da Pontificia Universidade Católica do Rio Grande do Sul (PUCRS), em Porto Alegre, RS, Brasil. 
Endereço para correspondência

Cláudio Primo Delanoy

Pontificia Universidade Católica do Rio Grande do Sul

Av. Ipiranga, 6.681, Prédio 8, sala 401.14

Partenon, 90619-900

Porto Alegre, RS, Brasil 